\title{
Fenestration of the Supraclinoid Internal Carotid Artery
}

\author{
J. Max Findlay, Mario Chui and Paul J. Muller
}

\begin{abstract}
A twenty-eight year old woman presenting with subarachnoid hemorrhage was found at angiography to have a left anterior cerebral-anterior communicating artery aneurysm. Also identified was a fenestration of the right supraclinoid internal carotid artery with an associated accessory middle cerebral artery. This appears to be the second reported case of fenestration of the intracranial internal carotid artery. Fenestrations of cerebral vessels and their possible embryologic origins are briefly reviewed.
\end{abstract}

RÉSUMÉ: Fenestration de la portion supraclinoïdienne de l'artère carotide interne À l'angiographie, on a découvert, chez une femme âgée de vingt-huit ans présentant une hémorragie sous-arachnoïdienne, un anévrisme impliquant l'artère cérébrale antérieure gauche et la communicante antérieure. On a également décelé une fenestration de la portion supraclinoïdienne de la carotide interne droite avec une artère cérébrale moyenne accessoire associée. Il semble que le cas présente soit le deuxième cas de fenestration de la portion intracrânienne de la carotide interne rapporté dans la littérature. Nous revoyons les fenestrations des vaisseaux sanguins cérébraux et leurs origines embryonnaires possibles.

Can. J. Neurol. Sci. 1987: 14:159-16I

Fenestration or segmental duplication of the cerebral vessels is rare but well recognized in certain locations, such as the vertebrobasilar, anterior and middle cerebral arteries. Fenestrations have been found related to aneurysms, with the aneurysm occurring at the fenestration or at a site separate from it. We describe a patient with a fenestration of the right supraclinoid internal carotid artery found after subarachnoid hemorrhage from an anterior communicating artery aneurysm.

\section{CASE REPORT}

A twenty-eight year old woman was seen at our hospital after collapsing at home with a brief loss of consciousness. She awoke with a severe headache and complained of transient binocular loss of vision. On examination, she was uncomfortable, somnolent and confused. Nuchal rigidity was present but there were no focal neurological signs. A computerized tomographic (CT) scan showed dense blood clot in the basal cisterns. Twelve hours later, she underwent cerebral angiography, which revealed a small left anterior cerebral-anterior communicating aneurysm. There was also a fenestration of the right supraclinoid internal carotid artery just above the origin of the ophthalmic artery and below the origin of the anterior choroidal artery arising from the supraclinoid carotid artery (Figure 1-4). Different oblique projections failed to demonstrate any associated fenestration aneurysm.
Immediately following angiography, she underwent a left pterional craniotomy and the aneurysm neck was clipped uneventfully. The fenestration of the opposite internal carotid artery was not visualized at operation. The morning following surgery she was drowsy but following commands and she continued to do well until the eighth day after hemorrhage when she became drowsy and right hemiparetic. A cerebral angiogram showed left proximal middle cerebral and bilateral anterior cerebral vasospasm. The aneurysm was obliterated by the clip and the fenestration was again noted. A balloon-tipped pulmonary artery catheter was inserted and volumn augmentation with hemodilation carried out, with subsequent clinical improvement. Ultimately, she made a complete neurologic recovery and was discharged home nineteen days after surgery.

\section{Discussion}

Congential variations of the cerebral vessels are common, with a balanced "classic" circle of Willis configuration present in only approximately eighteen percent of specimens. ${ }^{1.2}$ The commonest variations consist of hypoplastic or absent segments of the circle, such as the posterior communicating artery, ${ }^{3}$ the proximal (A1) segment of the anterior cerebral artery, ${ }^{4}$ and the precommunicating (Pl) segment of the posterior cerebral artery. ${ }^{3}$ Fenestrations or segmental duplications of cerebral

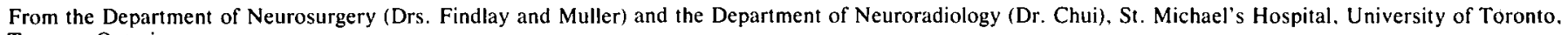
Toronto, Ontario

Received July 3, 1986. Accepted November 26, 1986

Reprint requests to: Dr. P.J. Muller, Chief, Division of Neurosurgery, 38 Shuter Street, Toronto, Ontario, Canada M5B 1 A6 


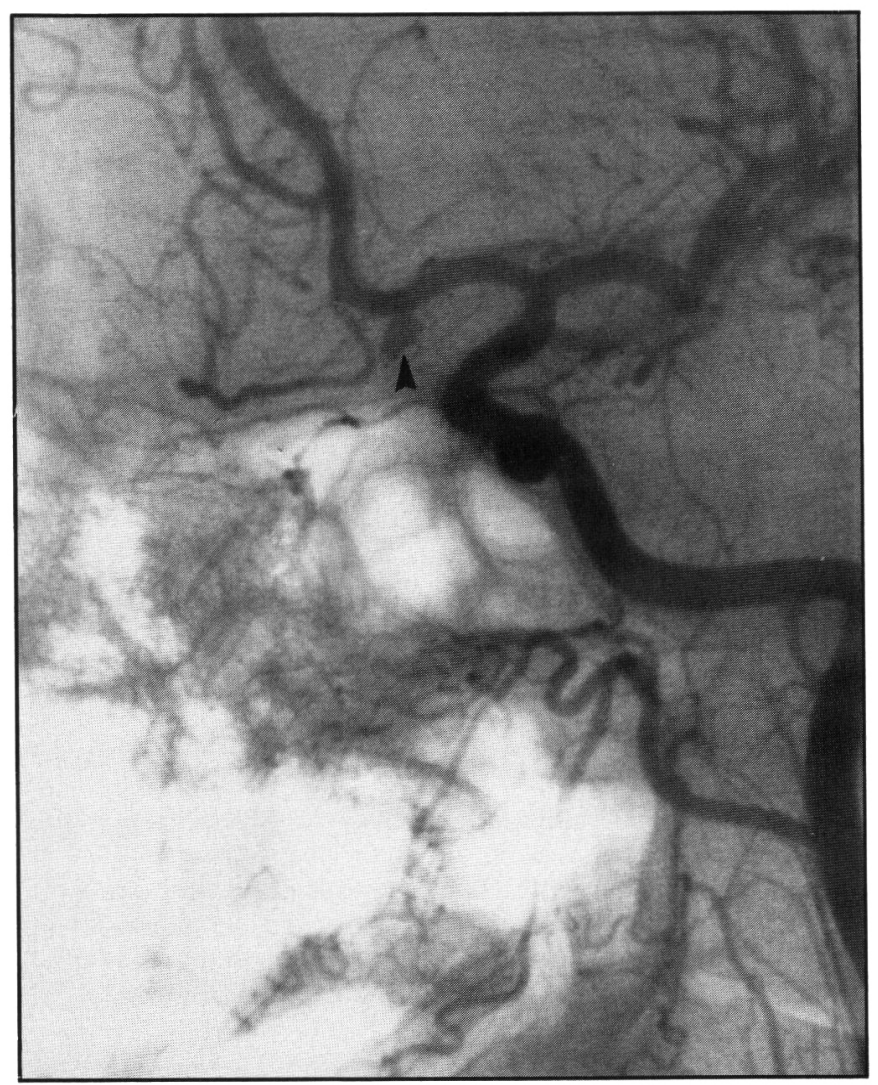

Figure I - Anteroposterior oblique view, left common carotid angiogram. A small aneurysm at the left anterior cerebral-anterior communicating complex (arrowhead) was shown.

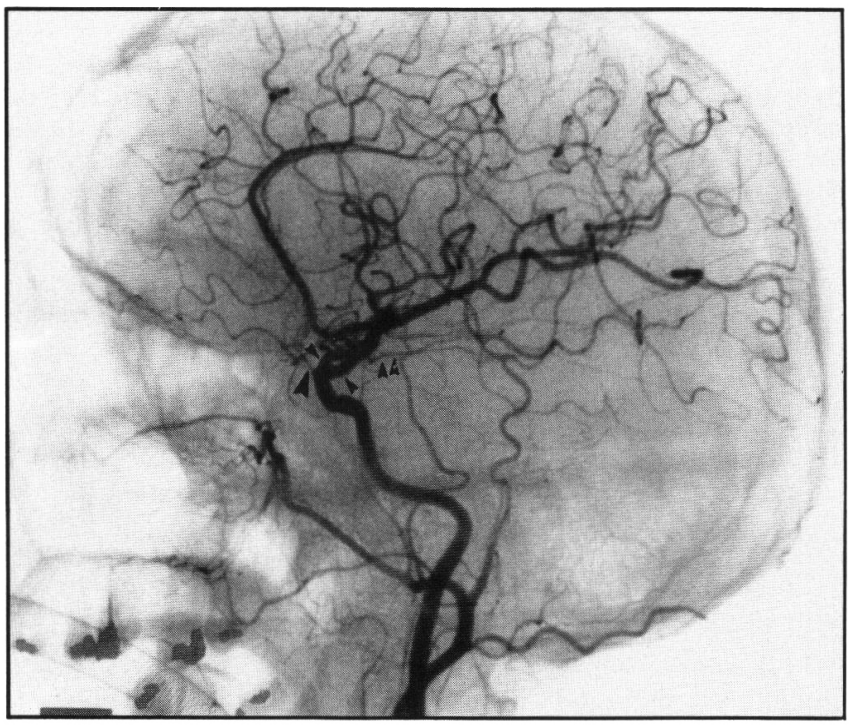

Figure 3 - Lateral view, right common carotid angiogram. The fenestration (opposing arrowheads) was seen between the ophthalmic (large arrowhead) and the anterior choroidal arteries (double arrowheads).

arteries are much less common than segmental hypoplasia or aplasia. Fenestrations have been most frequently noted in the vertebral ${ }^{5-8}$ and basilar arteries. ${ }^{6.9-15}$ Present in up to five percent of autopsy specimens ${ }^{16}$ basilar artery fenestration has been attributed to failure of the paired longnitudinal neural arteries to fuse in the 5-7 mm embryo. ${ }^{17}$ Fenestration of the anterior cerebral, ${ }^{18}$ anterior communicating ${ }^{4}$ and middle cere-

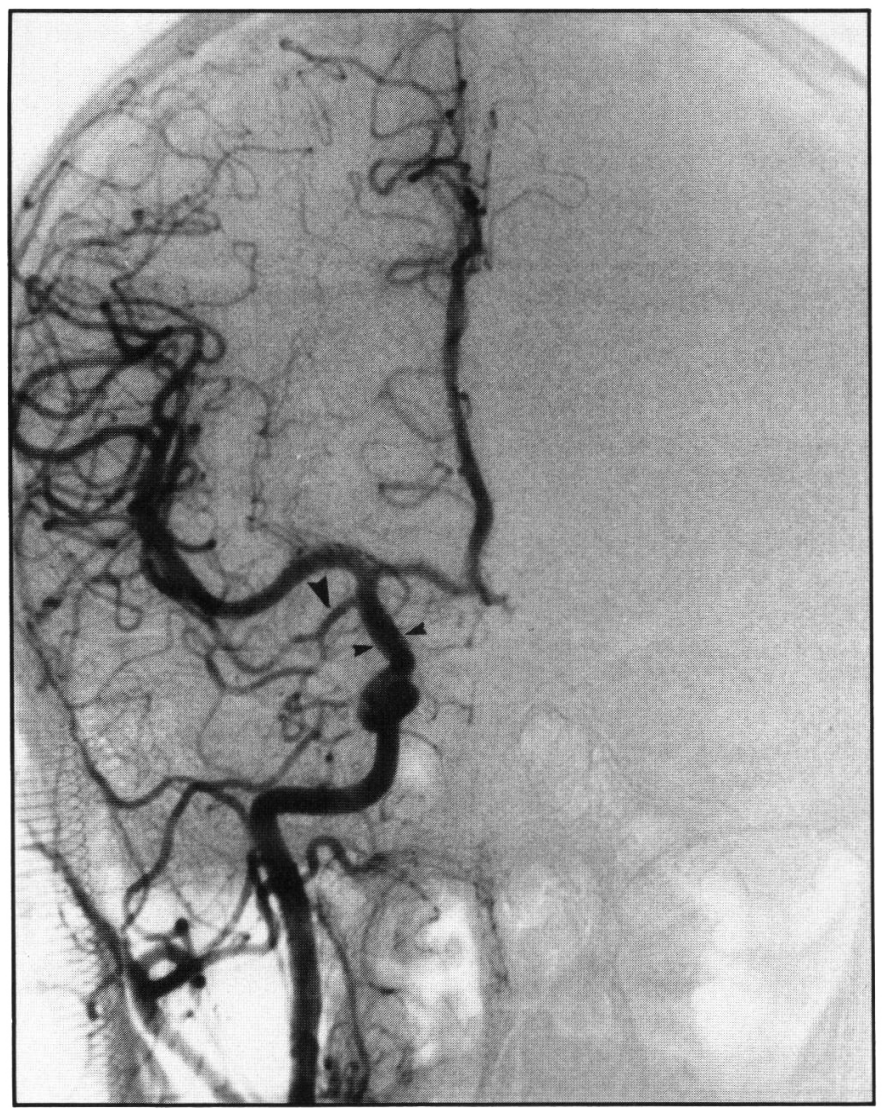

Figure 2 - Anteroposterior view, right common carotid angiogram. The supraclinoid internal carotid fenestration was superimposed upon itself as a double density (opposing small arrowheads). The accessory middle cerebral artery (large arrowhead) was also well shown.

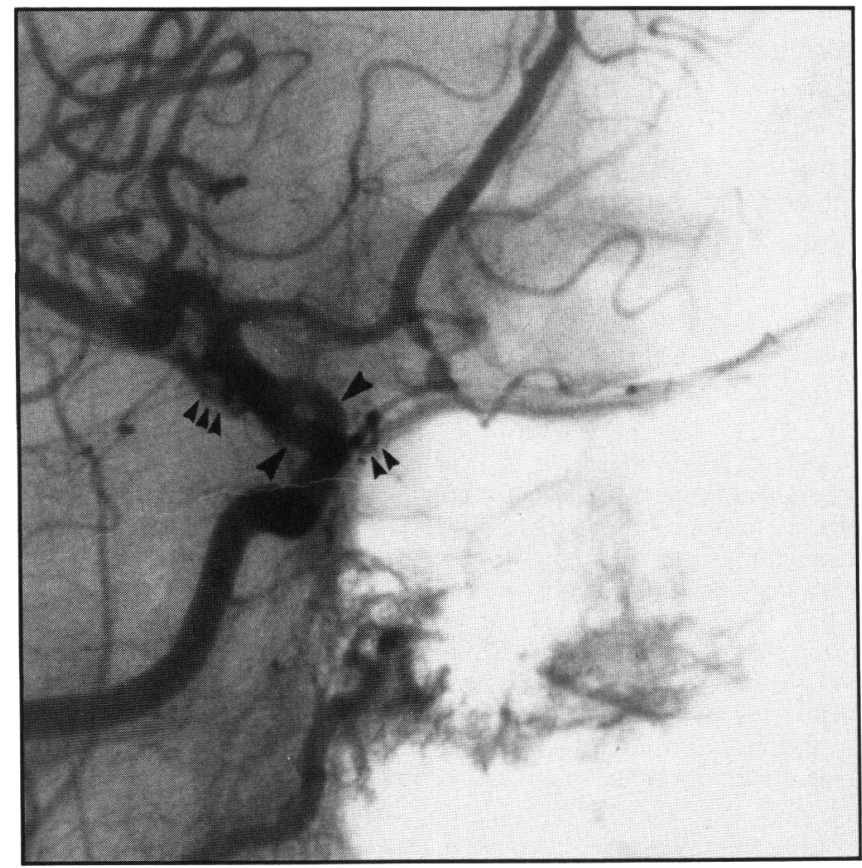

Figure 4 - Anteroposterior oblique view, right common carotid angiogram. The fenestration (opposing arrowheads) was shown just above the ophthalmic artery (double small arrowheads). The accessory middle cerebral artery, however, was superimposed upon itself proximally (triple small arrowheads). The left anterior cerebral-anterior communicating aneurysm was also faintly opacified. 
bral arteries ${ }^{6,19-22}$ have also been reported, and are thought to represent persistent embryonic anastomoses from the primitive vascular network formed between the anterior cerebral and middle cerebral arteries in the embryo of $4.5 \mathrm{~mm} .{ }^{17}$ Supraclinoid internal carotid artery duplication appears to be extremely rare, with only one case reported previously. ${ }^{23}$ The duplicated segment in our patient, and in the single case reported ${ }^{23}$ appears to begin near the ophthalmic artery which corresponds to the point of division of the primitive internal carotid artery into its cranial and caudal branches (embryo $4 \mathrm{~mm}$ stage). ${ }^{17} \mathrm{~A}$ fenestration at this location may therefore represent a plexiform bifurcation of the primitive internal carotid into its cranial division, which gives rise to anterior choroidal, middle and anterior cerebral arteries, and its caudal division which terminates as the posterior communicating artery. ${ }^{17}$

There appears to be an association between fenestrations and cerebral aneurysms. ${ }^{15}$ Aneurysms can occur at the proximal end of the fenestration, arising at the bifurcation of the parent vessel into the duplicated segment, $, 911.12 .13,15.22 .23$ more rarely they can occur at the distal end of the fenestration, ${ }^{14}$ and finally, as in our case, they can occur remote from the fenestration. ${ }^{5.22}$ In the previously reported case of intracranial internal carotid artery fenestration, the patient presented with rupture of a small proximal fenestration aneurysm. ${ }^{23}$ In a careful morphologic and histologic study of a basilar artery fenestration and proximal fenestration aneurysm that had bled fatally Black and Ansbacher identified a ventral defect in the muscularis layer of the vessel at each end of fenestration, and showed that in their specimen the aneurysm arose at the proximal vessel wall defect. ${ }^{15}$ These defects occurred where fusion of the embryonic vessels stopped, giving rise to the intervening segment of duplicated vessels, and these vessels proved histologically normal. They speculated that these sites of structural wall weakness, combined with local hemodynamic forces present particularly at the proximal fenestration bifurcation, ${ }^{24}$ were predisposed to aneurysm formation. The rarer distal fenestration aneurysms most likely arise at the distal vessel wall defect. ${ }^{14}$ Whether or not aneurysms that arise separate from the fenestration represent concurrent congenital anomalies of embryonic fusion, as some have suggested, ${ }^{22}$ is conjecture at this time.

\section{REFERENCES}

1. Alpers BJ, Beery RG, Paddison RM. Anatomical studies of the circle of Willis in normal brain. Arch Neurol Psychiatry 1981; 409-418.
2. Riggs HE, Ropp C. Variations in form of the circle of Willis. Arch Neurol 1963; 8: 24-30.

3. Saeki N, Rhoton AL Jr. Microsurgical anatomy of the upper basilar artery and the posterior circle of Willis. J Neurosurg 1977:46: 563-578.

4. Perlmutter D, Rhoton AL Jr. Microsurgical anatomy of the anterior cerebral-anterior communicating artery complex. J Neurosurg 1976; 45: 259-272.

5. Miyazaki S, Kamata K, Yamaura A. Multiple aneurysms of the vertebro-basilar system associated with fenestration of the vertebral artery. Surg Neurol 1981; 15: 192-195.

6. Teal JS, Rumbaugh CL, Bergeron RT, Segall HD. Angiographic demonstration of fenestrations of the intradural intracranial arteries. Radiology 1973; 106: 123-126.

7. Kowada M, Takahashi M, Gito Y, Kishikawa T. Fenestration of the vertebral artery. Neuroradiology 1973; 6: 110-112.

8. Lasjaunias P, Braun JP, Hasso AN, Moret J, Manelfe C. True and false fenestration of the vertebral artery. J Neurorad 1980: 7: 157-166.

9. Hoffman WF, Wilson CB. Fenestrated basilar artery with an associated saccular aneurysm. J Neurosurg 1979; 50: 262-264.

10. Takahashi M, Tamakawa Y, Kishikawa T, Kowada M. Fenestration of the basilar artery. Radiology 1973; 109: 79-82.

11. Becker D, Hamilton R. Saccular aneurysm associated with fenestrated basilar artery: Case report. Neurosurgery 1979;5:695-697.

12. Hemmati M, Kim K. A ruptured aneurysm at the basilar artery fenestration. Radiology 1979; 174: 130.

13. Matricali B, Van Dulken H. Aneurysm of fenestrated basilar artery. Surg Neurol 1981; 15: 189-191.

14. Andrews BT, Brant-Zawadzki M, Wilson CB. Variant aneurysms of the fenestrated basilar artery. Neurosurgery 1986; 18: 204-207.

15. Black SPW, Ansbacher LE. Saccular aneurysms associated with segmental duplication of the basilar artery. J Neurosurg 1984; 61: 1005-1008.

16. Wollschlaeger G, Wollschlaeger P, Lucas F, Lopez V. Experience and result with postmortem cerebral angiography performed as routine procedure of the autopsy. A J R 1967: 101: 68-87.

17. Padjet $\mathrm{DH}$. The development of cranial arteries in the human embryo. Contrib Embryol 1948; 32: 205-267.

18. Ito J, Washiyama K, Kim C, Ibuchi Y. Fenestration of the anterior cerebral artery. Neuroradiology 1981;21:277-280.

19. Ito J, Maeda H, Inoue K, Onishi Y. Fenestration of the middle cerebral artery. Neuroradiology 1977; 13: 37-39.

20. Krompton MR. The pathology of ruptured middle cerebral artery aneurysms. Lancet 1962; $2: 421-425$.

21. Lazar M, Bland J, North R, Bringewald P. Middle cerebral artery fenestration. Neurosurgery 1980; 6: 297-300.

22. Ueda T, Goya T, Wakisaka S. Kinoshita K. Fenestrations of the middle cerebral artery associated with aneurysms. A J N R 1984; 5: 2639-2640.

23. Yock DH. Fenestration of the supraclinoid internal carotid artery with rupture of associated aneurysm. A J N R 1984; 5: 634-636.

24. Ferguson GG. Physical factors in the initiation, growth and rupture of human intracranial sacular aneurysms. J Neurosurg 1972; 37 : 666-667. 